Water within, moving through, and shaping the Earth's surface: Introducing a Special Issue on Water in the Critical Zone

Running title: Special Issue on Water in the Critical Zone

Ying Fan, Department of Earth and Planetary Sciences, Rutgers University, New Brunswick, NJ, USA OrcID 0000-0002-0024-7965

Gordon Grant, Pacific Northwest Research Station, USDA Forest Service, and College of Earth Ocean and Atmospheric Sciences, Oregon State University, Corvallis, OR, USA

Suzanne P Anderson, Dept. of Geological Sciences and INSTAAR, University of Colorado, Boulder, CO, USA

OrcID 0000-0002-6796-6649

\title{
Acknowledgements
}

We thank all the authors of this special issue for their contributions and the many reviewers who provided insightful and constructive suggestions. SPA acknowledges support from NSF-EAR-1331828, and YF from NSF EAR 1528298. As we write this introduction, our hearts are heavy with the far-tooearly loss of our colleague, Professor Henry Lin, whose tireless leadership and effort to integrate hydrologic processes into $\mathrm{CZ}$ sciences will continue to inspire us and guide us as we advance our sciences. 


\section{The Special Issue}

As the sole habitat for terrestrial life, the Earth's Critical Zone (CZ) refers to the upper, porous layer of the continental crust that is interacting with the circulating meteoric waters. Conceptually, water is central to the intriguing co-evolution of both the hydrologic behavior and the structure of the CZ. On one hand, the path and rate of water circulating through the CZ are shaped by the CZ physical structure itself, such as the distribution of material porosity and permeability. On the other hand, and at longer time scales, the circulating water shapes the $\mathrm{CZ}$ structure through physical and chemical alterations of porosity and permeability, and through being an agent of denudation, thereby reshaping the surface of the $\mathrm{CZ}$ and shifting its hydraulic boundaries. It is possible to alternate between thinking of the $\mathrm{CZ}$ as a storage container for water, or thinking of water as an agent shaping $\mathrm{CZ}$ architecture, in much the same way that its possible either to see a vase or to see profiles of two faces in the classic Rubin's vase illusion (Figure 1). This perspective shifting duality of the water-CZ relationship is further modulated by biological forces such as plants and soil organisms, as well as anthropogenic actions that both alter the flow and chemistry of the water in the CZ. How the modern-day CZ structure shapes current hydrologic processes, how vegetation and humans alter the hydrology and biogeochemistry of the $\mathrm{CZ}$, and how the hydrology and $\mathrm{CZ}$ structure co-evolve via feedbacks arising from this duality of the water- $\mathrm{CZ}$ relationship, are the three broad categories of questions that motivated this collection of 20 papers comprising the Special Issue of Hydrological Processes on Water in the Critical Zone. A brief introduction to the contributions organized by these overarching questions follows.

\section{How does modern-day CZ structure influence water storage and flow paths?}

In examining how the modern-day CZ structure influences water storage and flow paths, an obvious first step is to characterize the subsurface, i.e. to determine the shape of system. Two papers delve deep to reveal CZ structure with geophysical techniques. Based on 30 seismic profiles, 7 
downhole nuclear magnetic resonance and sonic logs, petrophysical models, push-core rock sampling, Bayesian inversion, and kriging-based extrapolation, Flinchum et al. (2018) (the 2019 MG Anderson Editor's Choice Award winner for Outstanding Paper of the Year) mapped the 3-dimensional (3D) porosity structure of the saprolite and fractured rock under a granite hill in Wyoming, to a depth of 80 meters. Geophysical inversion techniques allowed the authors to infer the porosity structure, CZ depth, and total water storage capacity in the saprolite and bedrock. Geostatistical interpolation further enabled the characterization and visualization of the 3D CZ structure below the surface. Using electrical resistivity tomography (ERT) imaging, Chen et al. (2018) acquired 4 profiles across a cockpit karst catchment in southwestern China, revealing complex heterogeneity in the karst subsurface. The authors combined this geophysical characterization with observations of groundwater level, spring discharge, water temperature and $\mathrm{O}$ and $\mathrm{H}$ isotopic response to precipitation events, to construct a detailed conceptual model of hydrologic connectivity in this complex terrain. These studies demonstrate the power and feasibility of geophysical imaging and inversion techniques in offering the most direct, firstorder observation of the subsurface structure, the single most important control on subsurface water storage and flow paths. In addition, knowing the 3D CZ structure provides critical guidance on how field instruments should be deployed across a catchment, depths of the subsurface that need be sampled, and how a hydrologic and geochemical model should be constructed. At a higher level, such geophysical imaging has revealed new patterns and generated new hypotheses on processes that may have shaped the CZ depth structures (e.g., Anderson et al., 2013; Rempe and Dietrich, 2014; St. Clair et al., 2015; Anderson et al., 2019; see also review by Riebe et al., 2017). If seeing is critical to learning, then geophysical imaging should be considered a first step in CZ characterization.

Subsurface hydrologic storage and connectivity can also be inferred, to some extent, from geochemical studies that trace the origins of stream water based on stream geochemistry, as exemplified by a number of studies in this volume (Carroll et al., 2018; Chen et al., 2018; Clow et al., 
2018; Foks et al., 2018; Dwivedi et al., 2018; Godsey et al., 2019; Rose et al., 2018). Several of these studies focus on water sources (e.g. rain or snow) to streamflow, and how CZ architecture shapes flowpaths and consequently water transit times. Using observations of $\mathrm{H}$ and $\mathrm{O}$ isotopes, major ions, trace metals, dissolved organic (DOC) and inorganic carbon (DIC), and stream discharge, and applying a multivariate mixing model of rain, snow, groundwater as end members across 11 nested basins, Carroll et al. (2018) partitioned streamflow contribution from each of the endmembers in a snow-dominated catchment (East River) in the upper Colorado drainage. They found that groundwater contribution to streamflow is significant even in this steep terrain with thin soil, where groundwater has been considered negligible. Clow et al. (2018) assessed how land steepness, soil thickness and vegetation cover control water transit times and buffer acid rain and atmospheric $\mathrm{N}$ deposition, based on observed seasonal changes in $\mathrm{O}$ isotopes in both precipitation and streamflow across 11 headwater catchments in the western US. They found that catchments with steep slopes, high fraction of barren rocks, and low vegetation cover have the lowest groundwater storage, the highest young water fraction, and shortest mean transit time, and predict these catchments will have the lowest acid-buffering and $\mathrm{N}$-assimilation capacity. To quantify water and solute sources that contribute to stream flow in the alpine catchment of Andrews Creek, Colorado, and the seasonal and interannual variabilities of these sources, Foks et al. (2018) performed PCA and end-member mixing analysis, including snow, rain, soil water, and talus groundwater, based on 22 years of observed flow and fluxes of major ions and isotopes, observing interannual changes and trends. Key findings are that seasonal patterns in snow, rain, soil water, and talus groundwater contributions reflect seasonal snowpack, flushing of soil water had a large effect on stream chemistry during spring snowmelt despite only contributing a small fraction to streamflow volume, snow contributed large amounts of water with low concentrations of weathering products, interannual patterns reflected drought and wet periods, and talus groundwater contribution has increased overtime. 
The recent 2 water world hypothesis (2WW, e.g., McDonnell, 2014; Evaristo et al., 2015; Good et al., 2015) suggests that infiltrating precipitation (P) is partitioned into two distinct storage reservoirs that exit the catchment through distinct paths. One reservoir is the groundwater that discharges to streams, which has similar $\mathrm{O}$ and $\mathrm{H}$ isotopic signatures as precipitation. The other is comprised of shallow soil water and plant xylem water, which are isotopically enriched from evaporative fractionation. To understand this partitioning of subsurface water storage, Dralle et al., (2018) quantified the direct storage (Sd) that discharges into streams, and the indirect storage (Sid) that is consumed by evapotranspiration (ET), at two sites with very different lithology and CZ depth, but under the same climate. Based on seasonal observations of $P$, hillslope and catchment outflow, water table level, and ET estimates at daily time steps over one year, and seasonal water balance studies, they found that, in the Elder Creek basin with a thick weathered zone, Sid consists of unsaturated soil and rock moisture $(\sim 400 \mathrm{~mm})$, and Sd reflects the saturated groundwater $(\sim 78 \mathrm{~mm})$. But in Dry Creek with a mixed rock melange lithology and a thin weathered soil zone, the shallow, perched and ephemeral water table is accessible to ET, and thus Sid includes both the unsaturated plus some of the saturated storage ( 200m), and Sd is the saturated storage only when the water table is high and laterally connected to streams ( $12 \mathrm{~mm})$. This study not only sheds light on the $2 \mathrm{WW}$ perspective, but also highlights the lithology as a dominant control on hydrologic connectivity and storage partitioning, through its influence on CZ development.

Dwivedi et al (2018) explored various subsurface storage terms, their seasonal dynamics and drivers, role in explaining stream chemistry, and the proportion of deeper groundwater flow that sustains dry-season streamflow and shapes porosity development at the Santa Catalina Mountains Critical Zone Observatory in Arizona. They incorporated precipitation, streamflow, soil moisture, shallow and deep groundwater level, water age, as well as 42 chemical species in stream water over multiple years into a PCA and end member mixing model (EMMA) to identify end members contributing to 
streamflow and water chemistry. Conceptual models of seasonal hydrologic storage filling and release were constructed for the winter wet season (with maximum dynamic storage of $~ 55 \mathrm{~mm}$ ), summer monsoon season $(\sim 17 \mathrm{~mm})$, and summer dry season $(\sim 7 \mathrm{~mm})$. They found that $\mathrm{P}$ contributes to $39-69 \%$ of streamflow, soil water contributes $25-56 \%$, shallow groundwater contributes $1-5 \%$, deep groundwater contributes $0-3 \%$, and over the long term only $1.4 \%$ of annual P becomes deep $\mathrm{CZ}$ groundwater flux that influences deep rock weathering and CZ development. The study also demonstrated a strong and positive correlation between dynamic storage and stream-water geochemical heterogeneity.

Seasonal dynamics of stable isotopes in the soil water reflect precipitation source and competing shallow $\mathrm{CZ}$ processes such as evaporative fractionation and infiltration mixing, which vary with climate, terrain and vegetation. Sprenger et al (2018) examined soil water $\mathrm{O}$ and $\mathrm{H}$ isotopes in 5 catchments in the northern latitudes, spanning a range of $\mathrm{P}$ characteristics and across multiple seasons, to evaluate how the source, fractionation and mixing vary with $\mathrm{P}$ input, vegetation, and topography. They found that although higher temperatures lead to higher soil evaporation that kinetically fractionates the soil water isotopes, mixing with infiltrated precipitation that is unfractionated was the dominant driver of soil water deviation from the local meteoric water line among the 14 sampling locations. The resulting memory effect results in an evaporation fractionation of soil waters that is most intense during autumn.

Finally, focusing on how CZ structure influences stormflow/baseflow partitioning, Zimmer and Gannon (2018) asked: from the Appalachian Mountains to the Piedmont, how do systematic changes in climate and weather, CZ depths, and CZ stratigraphy drive differences in runoff characteristics and baseflow-stormflow partitioning? Analyzing daily P and USGS streamflow from 39 Appalachian watersheds and 34 watersheds in the Piedmont, the authors found that higher $\mathrm{P}$ led to higher runoff ratio (streamflow/P) in the Appalachians $(0.4-0.55)$ as compared with the Piedmont $(0.25-0.33), \mathrm{CZ}$ depth is not a dominant control on streamflow across these provinces, but helps explain seasonal 
variations in stormflow/baseflow partitioning, and ubiquitous, shallow impeding layers in the Piedmont drive rapid lateral stormflow and reduce percolation of water to deeper storage zones, which reduces the ability for Piedmont watersheds to buffer variability in P and ET demand.

\section{How do vegetation and humans shape the $\mathrm{CZ}$ ?}

Vegetation, particularly trees with substantial root systems, can influence Earth surface processes in profound ways (e.g., Brantley et al 2016). Many of the pathways whereby vegetation shapes the $\mathrm{CZ}$ are through influencing the quantity and chemistry of water circulating through the $\mathrm{CZ}$. Jin et al (2018) monitored soil moisture profiles to $1 \mathrm{~m}$ depth under forested and grassland catchments on the Chinese Loess Plateau. Over the growing season of 2016, P infiltrated faster and deeper in forested sites, and forest sites in the valleys experienced the most complete dry-down due to higher plant biomass. Using Self-Potential techniques, Voytek et al (2019) detected diurnal soil moisture movement toward a transpiring tree, consistent with sap flow measurements and a coupled electric and soil water flow model. Sprenger et al (2018) also detected a vegetation signal in soil water isotopic fractionation.

How vegetation relies on and depletes $\mathrm{CZ}$ water storage during multi-year droughts is a question of consequence to understanding both $\mathrm{CZ}$ subsurface water dynamics and ecosystem resilience and forest mortality in a drying and warming climate in the western US. Rungee et al (2019) estimated subsurface water storage replenishment and plant water-use based on monthly water budget analysis at 25 flux tower sites in the western US, covering 5 vegetation types. They found that at sites with Mediterranean climate, $\sim 52 \%$ of annual ET comes from seasonal drawdown of subsurface water storage; at sites under summer monsoon, subsurface water supported $\sim 29 \%$ of annual ET. At the warmer sites, ET exceeded P in more than half of the observation years as it is buffered by subsurface storage, and the studied sites maintained wet-year ET rates for 8-33 months before attenuation. These 
findings have implications for understanding the depth and capacity of CZ water storage, as well as depth of plant root systems that enable vegetation to tap into deep moisture sources.

The impact of vegetation on the CZ was examined by Robinet et al (2018), who explored difference in the structure, hydrology, and geochemistry between natural forests and croplands in subtropical southern Brazil, where agriculture is fast expanding. The authors monitored stream, , pore, subsurface, and rain water for dissolved silicon concentration (DSi) and O-H isotopes, to identify contributing sources to streamflow under forest vs. agriculture landcover. They found that in the forested catchment a dense macropore network combined with a compact B-horizon led to rapid subsurface stormflow, and the chemical signature of old stream water was similar to shallow groundwater and pore soil water The agricultural catchment sees increased streamflow and rapid response to rainfall, mostly due to greater surface runoff.

In addition to replacing natural vegetation with agricultural landcover, humans also directly regulate the storage, flow paths, and geochemistry of the CZ. Using a hydrology model driven by two future climate and six management scenarios (tile-drain removal, wetland reconstruction, riparian reforestation, and crop-rotation), Botero-Acosta et al (2018) simulated streamflow and groundwater level in the IML (Intensely Managed Landscape) CZO in Illinois. They found that removing tile-drain increases peak river flow and water table level, while wetland reconstruction and reforestation increases ET and reduces river flow.

In a comprehensive study of physical and chemical weathering rates, Floury et al (2019) asked : how does intensive farming impact chemical weathering in a carbonate rock terrain under temperate climate? What are the sources of solutes in the springs and streams (oceanic input through precipitation, fertilizer use, or carbonate rock weathering)? What are the physical and chemical denudation rates? Through multiple chemical tracers they found that river chemistry is dominated by 
rain (oceanic) input, fertilizer input is detectable and on the same order as oceanic input, rock weathering releases 5-7 times more than either, total denudation rate (physical + chemical, with chemical 10 times higher than physical) is $\sim 20 \mathrm{~mm} / \mathrm{ky}$, which is among the lowest chemical rates for carbonate terrain in temperate climates, and fertilizer use has enhanced carbonate dissolution. All have implications for understanding how hydrology, with and without humans, shapes the CZ over the long term.

\section{How do hydrology and CZ co-evolve via feedbacks?}

How hydrology shapes the CZ structure in the long term was directly and indirectly addressed by several papers in this collection. Direct coupling of hydrology and CZ development underlie three major contributions to the special issue: Anderson et al (2019), Harman and Kim (2019), and Harman and Cosans (2019). In a recent review and synthesis on process controls of deep CZ development, Riebe et al (2017) proposed four hypotheses that, (H1-tectonic) tectonic stress interacts with topographic stress to determine the depth of rock damage (St. Clair et al 2015), (H2-climatic) rock damage from frost action is deeper on the shady side of a ridgeline (Anderson et al 2013), (H3-hydrologic) groundwater drainage through bedrock, modulated by stream incision, sets the depth for physical and biogeochemical weathering (Rempe and Dietrich 2014), and (H4-geochemical) the weathering front is set by the kinetics of mineral dissolution and removal in the subsurface and its balance with the rate of physical erosion on the surface (Lebedeva and Brantley 2013). These four models view CZ development from more or less distinct disciplinary angles (tectonic, climatic, hydrologic, and geochemical), although all researchers acknowledge these processes are coupled in a real-world setting. The afore-mentioned three contributions to this special issue crossed these boundaries to shed light on the interceptions of processes governing CZ development. 
Anderson et al (2019) developed a model that couples hillslope hydrology (H3-hydrologic, Riebe et al 2017), reactive transport (chemical weathering) and surface erosion (H4-geochemical), in wet vs. dry climate scenarios (H2-climatic). Through simple formulations and analytical solutions of water flow and aging along streamlines (and feldspar removal) the authors could simulate the evolution of hillslope shape and weathering profile and front over a million years of geologic time. A key finding was that by varying the climate (and associated subsurface hydrology) alone from a humid to an arid setting, the model can produce plausible $C Z$ depth structures that are thicker under the topographic ridges, which has been observed from seismic imaging but attributed to tectonic compression- stress fields interacting with the topography (e.g., St. Clair et al., 2015). This result highlights the critical importance of recognizing how multiple driving forces and their interactions create the modern-day CZ structure.

Harman and Kim (2019) and Harman and Cosans (2019) presented a two-part series describing a model that coupled vertical (1D) chemical weathering and porosity development (H4-geochemical, Riebe et al 2017) and lateral (2D) subsurface hydrology under a hillslope (H3-hydrologic, controlling the kinetics of chemical weathering), and insights gained from this coupling. Part-1 (Harmon and Kim, 2019) discusses lateral flow processes in hillslopes and shows how lateral dimensions of advection-diffusionreaction equations can be collapsed, yielding a 1-D vertical equation in which the downward advective flux declines with depth. The model gives analytical insights on the controls of weathering front depth and weathering-product export pathways as functions of bedrock slope and uplift/stream incision rates. In Part-2 (Harmon and Cosans, 2019), they obtained an approximate analytical solution for the location and thickness of the weathering front within several hillslopes. Three pathways of solute export from hillslopes are identified: "diffusing up", where solutes diffuse upward and away from the weathering front into laterally flowing groundwater; "draining down", where solutes are advected primarily downward into unweathered bedrock; and "draining along", where solutes travel laterally within the 
weathering zone. Bedrock slope and stream incision rates determine the dominance of each pathway and the steady-state hillslope profile.

Indirectly, several studies (e.g. Chen et al 2018; Clow et al 2018; Dwivedi et al 2018; Floury et al 2018; Foks et al 2018; Rose et al 2018; Zimmer et al 2018) partitioned hydrologic flows into paths of different depths and quantified the rate and rhythm of deep groundwater flow, particularly through fractured bedrock, which does the most work in chemical weathering and flushing of weathering products. Additionally, studies of stream solute Concentration-Discharge (C-Q) relations give insights on flow paths and chemical weathering regimes (dilution, concentration, or chemostatic). Two papers focused on this subject: Rose et al (2018) analyzed the C-Q relationships to describe solute and sediment mobilization, reaction, and transport at event and longer timescales in White Clay Creek catchment in southeastern Pennsylvania. They collected and analyzed hourly samples over 44 events and found that negative $\log (C)-\log (Q)$ regression slopes, indicating dilution, dominate for geogenic solutes, whereas positive slopes, indicating concentration increase with discharge, were common for biologically associated solutes. Groundwater is the primary source of stormflow during the earliest and latest stages of events, whereas precipitation and soil water become increasingly connected to the stream near peak flow. In the contribution by Godsey et al (2019), the authors expanded their earlier, pioneering work on C-Q relations (Godsey et al 2009) based on data from 59 catchments, to include $>2000$ catchment worldwide from a recent global dataset covering a wider range of climate and lithological conditions. The C-Q relationships were explored at different time scales: event (using instantaneous $Q$ and $C$ measurements), annual (using annual mean $C$ and $Q$ values), and decades (>20yr mean $C$ and $Q$ values), the latter based on all sites but corrected for climate, lithology and landcover types. They found broad agreement with the earlier study. Major ions behave chemostatically at event and annual scales buffered by groundwater storage and fast chemical reactions, strong dilution at humid sites and week dilution at arid sites at decadal scales (correlating with climate). Biologically mediated species behave at 
near-chemostatic across all timescales and their long-term mean concentrations correlate more with landcover than climate.

\section{Looking forward}

The 20 contributions in this special issue addressed a wide range of questions regarding (1) how modern-day CZ structure influences hydrological processes, (2) how vegetation and human actions influence water quantity and chemistry in the $C Z$, and (3) how hydrology can shape $C Z$ depth and its structure in the long term. Drawing on these studies and looking forward, we see two broad areas in CZ research that can potentially accelerate our understanding and ability to predict CZ dynamics.

The first is the need to "see" the subsurface. Electromagnetic images extend our vision into the subsurface, a region that is otherwise opaque to human perceptions. State-of-science and inexpensive imaging and inversion techniques, such as reported in Flinchum et al (2018) and Chen et al (2018) in this special issue, hold great promises for quantifying the thickness, porosity profiles and hydraulic connectivity among different zones in the CZ. Such knowledge should be the target of first-order, reconnaissance-level investigations of CZ structure. Results should guide field work and modeling. Understanding water balance, flowpaths, and stream geochemistry can benefit greatly from a quantitative 3D visual model of CZ structure of catchments. Such a framework should provide a strong foundation for our understanding of biological systems, from microbial to forest stands.

The second is the need to integrate conceptual and numerical models that are developed separately by CZ scientists trained in different disciplines. The contributions by Anderson et al (2019), Harman and Kim (2019), and Harman and Cosans (2019) represent significant breakthroughs in demonstrating that it is indeed possible to construct simple, first-order, but critically linked process models at geologic time scales that shape the evolution of the $\mathrm{CZ}$. These models are not intended to 
simulate a particular site but serve as numerical laboratories to test hypotheses on the leading controls of CZ development, as exemplified by Anderson et al (2019), Harman and Kim (2019), and Harman and Cosans (2019). There are no better ways to test such hypotheses.

With critical zone science emerging as an extremely exciting and important nexus for researchers around the globe, we look forward to what future studies will reveal about this scientific frontier that lies so close to home and right under our feet. By bringing together a variety of perspectives on water in the Critical Zone, it is perhaps possible for a deeper understanding of CZ processes to emerge. With practice, it is easier to shift perspectives or to see multiple perspectives simultaneously, i.e., to see the $\mathrm{CZ}$ as a fixed structure that regulates water storage and transmission, and to see water as an agent that actively shapes CZ structure. We hope this Special Issue will serve as both a touchstone for where the science is today, and a spotlight illuminating where it needs to go.

\section{References}

Anderson RS, Anderson SP, Tucker GE. (2013) Rock damage and regolith transport by frost: an example of climate modulation of the geomorphology of the critical zone. Earth Surface Processes and Landforms 38: 299-316.

Anderson RS, Rajaram H, Anderson SP (2019) Climate driven coevolution of weathering profiles and hillslope topography generates dramatic differences in critical zone architecture. Hydrological Processes 33:4-19. https://doi.org/10.1002/hyp.13307

Botero-Acosta A, Chu ML, Stumpf AJ. (2018) Impacts of environmental stressors on the water resources of intensively managed hydrologic systems. Hydrological Processes 32:2947-2962.

https://doi.org/10.1002/hyp.13244

Brantley, Susan L., David M. Eissenstat, Jill A. Marshall, Sarah E. Godsey, Zsuzsanna Balogh-Brunstad, Diana L. Karwan, Shirley A. Papuga, Joshua Roering, Todd E. Dawson, Jaivime Evaristo, Oliver Chadwick, Jeffrey J. McDonnell, Kathleen C. Weathers (2017) Reviews and syntheses: on the roles trees play in building and plumbing the critical zone, Biogeosciences, 14, 5115-5142

Carroll RWH, Bearup LA, Brown W, Dong W, Bill M, Willlams KH. (2018) Factors controlling seasonal groundwater and solute flux from snow-dominated basins. Hydrological Processes 32:2187-2202. https://doi.org/10.1002/hyp.13151 
Chen X, Zhang Z, Soulsby C, et al. Characterizing the heterogeneity of karst critical zone and its hydrological function: An integrated approach. Hydrological Processes. 2018;32:2932-2946.

https://doi.org/10.1002/hyp.13232

Clow DW, Mast MA, Sickman JO. Linking transit times to catchment sensitivity to atmospheric deposition of acidity and nitrogen in mountains of the western United States. Hydrological Processes. 2018;32:2456-2470. https://doi.org/10.1002/hyp.13183

Dralle DN, Hahm WJ, Rempe DM, Karst NJ, Thompson SE, Dietrich WE. Quantification of the seasonal hillslope water storage that does not drive streamflow. Hydrological Processes. 2018;32:1978-1992. https://doi.org/10.1002/hyp.11627

Evaristo, J., Jasechko, S. \& McDonnell, J. J. Global separation of plant transpiration from groundwater and streamflow. Nature 525, 91-94 (2015)

Flinchum BA, Holbrook WS, Grana D, et al. Estimating the water holding capacity of the critical zone using near-surface geophysics. Hydrological Processes. 2018;32:3308-3326.

https://doi.org/10.1002/hyp.13260

Floury P, Gaillardet J, Tallec G, et al. Chemical weathering and $\mathrm{CO} 2$ consumption rate in a multilayeredaquifer dominated watershed under intensive farming: The Orgeval Critical Zone Observatory, France. Hydrological Processes. 2019;33:195-213. https://doi.org/10.1002/hyp.13340

Foks SS, Stets EG, Singha K, Clow DW. Influence of climate on alpine stream chemistry and water sources. Hydrological Processes. 2018;32:1993-2008. https://doi.org/10.1002/hyp.13124

Godsey, S. E., Kirchner, J. W., \& Clow, D. W. (2009). Concentration-discharge relationships reflect chemostatic characteristics of US catchments. Hydrological Processes, 23, 1844-1864.

http://doi.org/10.1002/hyp.7315

Godsey S., Hartmann J, Kirchner J (2019) Catchment chemostasis revisited: water quality responds differently to variations in weather and climate

Good, S. P., Noone, D. \& Bowen, G. Hydrologic connectivity constrains partitioning of global terrestrial water fluxes. Science 349, 175-177 (2015)

Harman CJ, Kim M. A low-dimensional model of bedrock weathering and lateral flow coevolution in hillslopes: 1. Hydraulic theory of reactive transport. Hydrological Processes. 2019;33:466-475.

https://doi.org/10.1002/hyp.13360

Harman, C. J., and Cosans, C. L. (2019) A low-dimensional model of bedrock weathering and lateral flow co-evolution in hillslopes: 2 . Controls on weathering and permeability profiles, drainage hydraulics, and solute export pathways. Hydrol. Process., https://doi.org/10.1002/hyp.13385.

Jin Z, Guo L, Lin H, et al. Soil moisture response to rainfall on the Chinese Loess Plateau after a long-term vegetation rehabilitation. Hydrological Processes. 2018;32:1738-1754.

https://doi.org/10.1002/hyp.13143 
Lebedeva MI, Brantley SL. 2013. Exploring geochemical controls on weathering and erosion of convex hillslopes: beyond the empirical regolith production function. Earth Surface Processes and Landforms 38: 1793-1807.

McDonnell, J. J. (2014), The two water worlds hypothesis: ecohydrological separation of water between streams and trees?. WIREs Water, 1: 323-329. doi:10.1002/wat2.1027

Rempe DM, Dietrich WE. (2014) A bottom-up control on fresh-bedrock topography under landscapes. Proceedings of the National Academy of Sciences 111: 6576-6581.

Riebe, C. S., W. J. Hahm, S. L. Brantley, and Landforms (2017) Controls on deep critical zone architecture: A historical review and four testable hypotheses, Earth Surf. Process. Landforms, 42: 128-156. doi: 10.1002/esp.4052.

Robinet J, Minella JPG, de Barros CAP, et al. Impacts of forest conversion and agriculture practices on water pathways in Southern Brazil. Hydrological Processes. 2018;32:2304-2317.

https://doi.org/10.1002/hyp.13155

Rose LA, Karwan DL, Godsey SE. Concentration-discharge relationships describe solute and sediment mobilization, reaction, and transport at event and longer timescales. Hydrological Processes.

2018;32:2829-2844. https://doi.org/10.1002/hyp.13235

Rungee J, Bales R, Goulden M. Evapotranspiration response to multiyear dry periods in the semiarid western United States. Hydrological Processes. 2019;33:182-194. https://doi.org/10.1002/hyp.13322

Schooler, J (2015) Briding the Objective/Subjective Divide- Towards a Meta-Perspective of Science and Experience. In T Metzinger \& JM Windt (Eds) OpenMIND: 34 (T) Frankfurt am Main: MIND Group. doi: 10.15502/9783958570405.

Sprenger M, Tetzlaff D, Buttle J, et al. Storage, mixing, and fluxes of water in the critical zone across northern environments inferred by stable isotopes of soil water. Hydrological Processes. 2018;32:17201737. https://doi.org/10.1002/hyp.13135

St. Clair J, Moon S, Holbrook WS, Perron JT, Riebe CS, Martel SJ, Carr B, Harman C, Singha K, Richter DD. (2015) Geophysical imaging reveals topographic stress control of bedrock weathering. Science 350: 534538.

Voytek et al (2019) Propagation of diel transpiration signals in the subsurface observed using the selfpotential method

Zimmer MA, Gannon JP. Run-off processes from mountains to foothills: The role of soil stratigraphy and structure in influencing run-off characteristics across high to low relief landscapes. Hydrological Processes. 2018;32:1546-1560. https://doi.org/10.1002/hyp.11488 


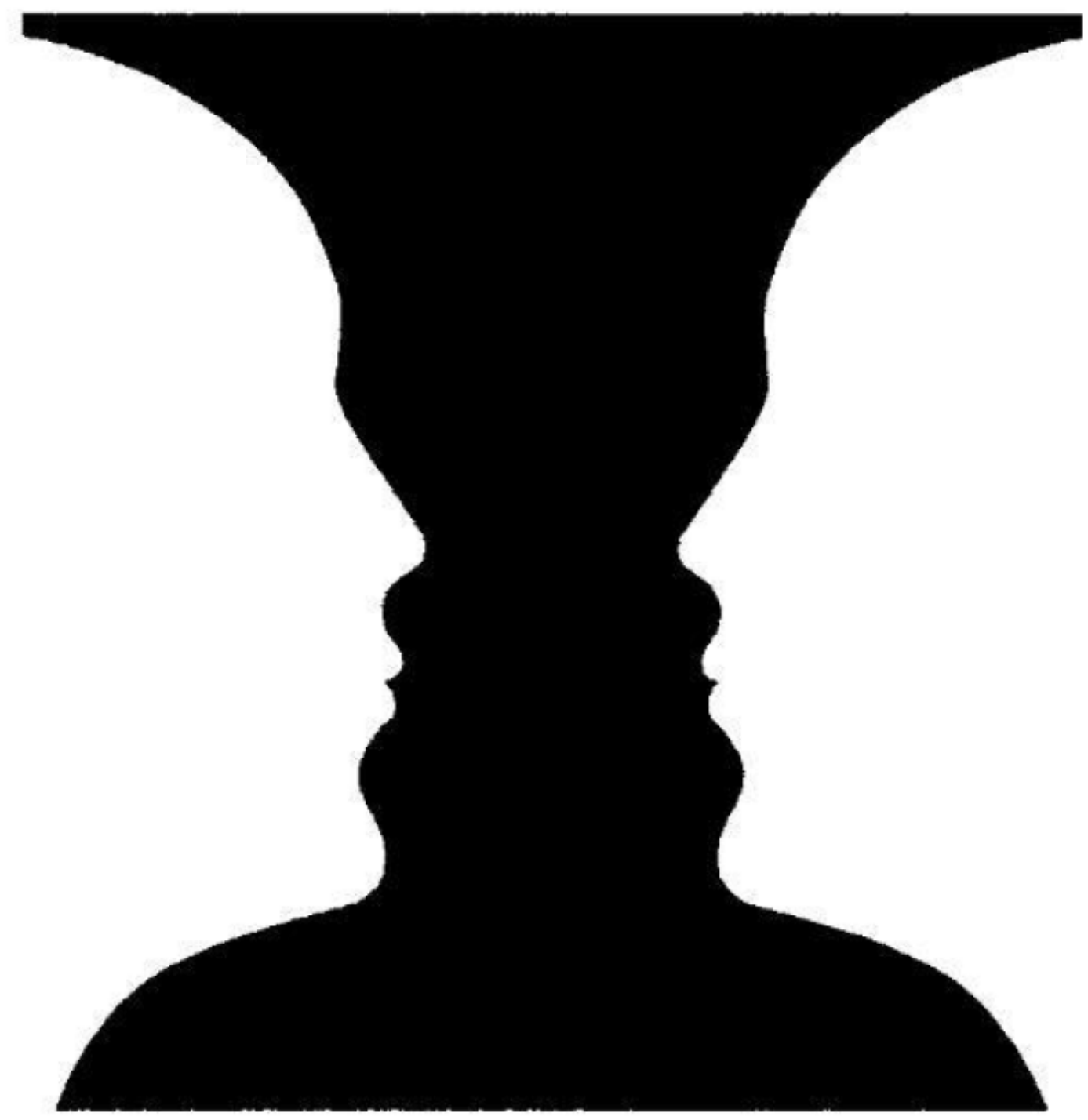

Figure 1. Rubin's vase, showing a silhouette of either a vase or profiles of two people. With permission from Schooler (2015). 